\title{
A PROSPECTIVE STUDY OF THE PATTERN OF USE OF ANTIMICROBIAL AGENTS IN SURGICAL PROPHYLAXIS IN A TERTIARY CARE CENTRE
}

\author{
C. S. BRETHIS ${ }^{*}$, S. THAMIZHARASAN ${ }^{2}$, S. A. SRIDEVI ${ }^{3}$, B. KALAISELVI ${ }^{4}$, M. BALAJI SINGH $^{5}$, K. VIJAYKUMAR $^{6}$ \\ 1,2,3,4Dept of Pharmacology, ACS Medical College and Hospital, Chennai India, ${ }^{5}$ Dept of Forensic Medicine, ACS Medical College and Hospital, \\ Chennai India, ${ }^{\circ}$ Dept of Pharmacology, Mahavir Institute of Medical Sciences, Hydrebad India \\ Email: csbrethis@yahoo.com \\ Received: 21 Oct 2016 Revised and Accepted: 24 Nov 2016
}

\begin{abstract}
Objective: To evaluate the most common class of antimicrobial agents used in surgical prophylaxis. To evaluate the timing, dosage, route and duration of use of antimicrobial agents in surgical prophylaxis.

Methods: The study subjects were 214 patients who underwent general surgical procedures at Vinayaka Missions Kirupananda Variyar Medical College from July 2013 to June 2014. The use of antimicrobial agents was noted from the first dose of antibiotic given before the induction of anaesthesia. After surgery was completed the duration of antibiotic in the post-operative ward was noted.

Results: Majority of the patients were males of age group 50-60 y and the most common surgical procedure was hernioplasty. Combination therapy with two antimicrobial agents was more preferred regimen 126 (58.9\%). Among the antimicrobial agent's cefotaxime 114 (24.8\%) was the most commonly prescribed drug and it was followed by metronidazole 121 (21.9\%). ceftriaxone 60 (13.1\%) was the third most commonly prescribed antimicrobial agent. The mean duration of prescription of antimicrobial agents in the present study was $4.78 \mathrm{~d}$ and the mean cost of drug treatment was 787.54 rupees. The cost-effective regimen was that of aminoglycosides and imidazole.
\end{abstract}

Conclusion: The choice of antimicrobial agent was based on the local prevalence pattern of microorganisms. The intravenous administration of antibiotic prophylaxis immediately before or after the induction of anaesthesia is the most reliable method for ensuring effective serum concentration at the time of surgery. The antimicrobial agent chosen must cover all the most likely contaminating organisms.

Keywords: Antimicrobial agents, Surgical prophylaxis

(C) 2017 The Authors. Published by Innovare Academic Sciences Pvt Ltd. This is an open access article under the CC BY license (http://creativecommons.org/licenses/by/4. 0/) DOI: http://dx.doi.org/10.22159/ijpps.2017v9i1.15803

\section{INTRODUCTION}

Antimicrobial resistance patterns can vary regionally and even among different hospitals within the same community. Overuse of antibiotics contributes to antimicrobial resistance and puts the patients at greater risk of carrying and becoming infected with resistant bacteria [1]. Drug utilisation research was defined by WHO as "the studies of marketing, distribution, prescription and use of drugs in society, with special emphasis on resulting medical, social and economic consequences" [2].

Human skin comprises of protective layers, and once the protective layer of skin is damaged, deep tissues are exposed to bacterial infection [3]. Semisynthetic antimicrobial agents like amikacin have resistance to bacterial inactivating enzymes [4]. Poorly managed surgical site infections may end in sepsis which is a widespread infection along with a significant mortality rate and major economic burden [5]. Antimicrobial agents along with vaccines represent most potential agents in preventing morbidity as well as mortality [6].

In India the prevalence of use of antimicrobial agents varies from 24$67 \%$ [7]. There is a strong relationship between the emergence of resistant strains of microorganisms and concurrent variations in antibiotic use in population over time [8]. Surgical site infections are the most common infections in surgical patients and lead to prolongation of hospital stay [9]. They lead on to complications like wound dehiscence, bleeding, cellulitis, septicaemia and death $[10,11]$.

The rate of occurrence of surgical site infections in clean surgeries is 1-5 \%, in clean-contaminated surgeries 6-9\%, in contaminated surgeries 13-20\%.[8,9] Pre-operative antibiotic therapy can reduce the incidence of surgical site infections $[14,15]$. The most common organisms causing surgical site infections are MRSA, Staphylococcus epidermidis, enteric gram+ve cocci [16, 17], gram-ve bacilli and anaerobes [18].
The use of antimicrobial agents before, during and after surgery is done to prevent post-operative complications [19]. Most common antibiotics used in surgical prophylaxis are cephalosporins. However, there are growing numbers of reports of resistance to these agents with increasing use [20]. In resistant cases, vancomycin is used. The other antibiotics used are metronidazole, gentamicin [21-23] and fluoroquinolones.

The development of modalities to effectively prevent and treat infection has occurred only within the last several decades [24].

\section{MATERIALS AND METHODS}

\section{Study center}

The study was conducted at Vinayaka Missions Kirupananda Variyar Medical College in the department of surgery from July 2013 to June 2014. During this period 214 patients who underwent general surgical procedures were taken up for the study.

\section{Inclusion criteria}

1. Patients aged between 20-60 y.

2. Both male and female patients.

3. Patients undergoing general surgical procedures.

\section{Exclusion criteria}

1. Patients with known hypersensitivity to antibiotics.

2. Patients with pre-existing infections.

3. Patients are undergoing minor surgical procedures.

4. Patients with renal impairment.

5. Patients with liver disease.

6. Diabetes mellitus patients.

7. Patients with malnutrition.

8. Immuno-compromised patients. 


\section{Study design}

This study is a single centre, prospective, open label and analytical study. The study was started after obtaining permission from the institutional ethical committee. The Institutional ethical committee permission letter no is VMKVMC/IEC/13/32 dated 30/01/2013. Before starting the study, a fully written informed consent in native language was obtained from all patients. The sample size was 214 patients. Patients were scrutinised for demographic data, clinical status, diagnosis, comorbid conditions, blood profile, current medication, past medical history and type of surgery to be performed.

All baseline characteristics were noted. The demographic data that were collected include patient's name, age, sex and address. The clinical status includes the vital signs, examination of cardiac status and other systems examination. The diagnosis was scrutinized to assess the type of surgery performed whether the surgery was clean, clean-contaminated or dirty. The blood profile was done to rule out diabetes mellitus, anaemia, immune-compromised state, renal insufficiency and hepatic insufficiency.

The past history was scrutinised for the history of hypertension, diabetes mellitus, drug allergies and surgical procedures. The data of the antimicrobial agents used include the generic name, the class of the antimicrobial agent, the timing of administration, the route of administration, dose, frequency of administration, duration, change of medication, combinations used, cost and the non-antimicrobial agents administered.

Patient's details were followed from the first dose of antibiotic given before the induction of anaesthesia. If the duration of surgery was longer than the half-life of the additional antibiotic dose of antibiotic given during surgery was noted. After surgery was completed the duration of antibiotic in the post-operative ward was noted. All information was obtained from the treatment chart, pre-operative checklist, anaesthesia records and patient's progress records.

Laboratory investigations done included both haematological examination and urine analysis. The haemoglobin level was estimated to rule out anaemia. The total count, differential count and erythrocyte sedimentation rate were done to rule out immunecompromised states and infectious conditions.

Blood sugar levels were determined to rule out diabetes mellitus. Serum urea and creatinine levels were assessed to evaluate the renal functions. Liver function tests were also done. Urine analysis was done to rule out the presence of sugar, proteins and pus cells.

\section{Statistical analysis}

The data obtained were entered in Microsoft excel spreadsheet and the analysis was done using SPSS software version 20.0. Descriptive statistical analysis was done by calculating frequency and the percentage for all the parameters. The valid percent and cumulative percent were also established.

\section{RESULTS \& DISCUSSION}

In the present study, the pattern of use of antimicrobial agents in surgical prophylaxis was assessed in 214 patients undergoing general surgical procedures. A total of 459 prescriptions were scrutinised to assess the prescribing pattern. Out of the total 214 patients, $33(15.5 \%)$ patients were in the age group of 20-29 y. About $39(18.3 \%)$ patients were in the age group of 30-39 y. In the age group of $40-49$ y there were $56(26.3 \%)$ patients. There were 72 $(33.8 \%)$ patients in the age group of $50-59 \mathrm{y}$. And in the age group of 60-69 y there were only $13(6.1 \%)$ patients. The majority of the patients belonged to the age group of $50-59 \mathrm{y}$.

This is similar to a study by Ajay khade et al. where the productive age group is actively involved in socioeconomic activities, making them vulnerable to diseases, which may need surgical interventions and antibiotic treatment [25]. The number of male patients in the study was $158(74.2 \%)$. The number of female subjects in the study was $55(25.8 \%)$. A Greater percentage of male subjects was included in the present study.

According to the Kuppusamy socioeconomic status scale, only 6 (2.8\%) patients belonged to upper socioeconomic status. About 24 $(11.2 \%)$ patients belonged to the upper middle class and 39 $(18.2 \%)$ patients belonged to the lower middle class. The majority of patients $82(38.3 \%)$ belonged to upper lower socioeconomic status followed by lower socioeconomic status $63(29.5 \%)$ patients. There is the need for cost-effective antimicrobial prophylaxis.

Among the general surgical procedures included in the study hernioplasty was the most common surgery encountered 109 (52.5\%). The second most common surgical procedure encountered in the present study was appendicectomy 34 (15.5\%). Followed by haemorrhoidectomy $30(14.1 \%)$. The number of patients who underwent modified radical mastectomy (MRM) was 15 (7\%). Only $8(3.8 \%)$ patients underwent lateral anal sphincterotomy for fissure in ano and hemi thyroidectomy for multinodular goitre. In the present study majority of the patients underwent clean surgical procedures and with the placement of implants like mesh in hernioplasty there is a need for prophylaxis against infections.

Table 1: Drug regimen in study subjects

\begin{tabular}{lllll}
\hline Regimen & Frequency & Percent & Valid percent & Cumulative percent \\
\hline Single Drug & 58 & 12.6 & 12.6 & 12.6 \\
Two Drug & 263 & 57.3 & 57.3 & 69.9 \\
Triple Drug & 138 & 30.1 & 30.1 & 100.0 \\
Total & 459 & 100.0 & 100.0 & \\
\hline
\end{tabular}

Table 2: Antimicrobial agents prescribed

\begin{tabular}{lllll}
\hline Generic name & Frequency & Percent & Valid percent & Cumulative percent \\
\hline Ceftriaxone & 131 & 13.9 & 13.9 & 13.9 \\
Cefotaxime & 195 & 20.7 & 20.7 & 34.6 \\
Amikacin & 93 & 9.9 & 9.9 & 44.5 \\
Gentamycin & 49 & 5.2 & 5.2 & 49.7 \\
Metronidazole & 180 & 19.1 & 19.1 & 68.6 \\
Tinidazole & 44 & 4.7 & 4.7 & 73.5 \\
Amoxicillin & 55 & 5.9 & 5.9 & 79.4 \\
Ampicillin & 66 & 7.1 & 7.1 & 86.5 \\
Ciprofloxacin & 97 & 10.3 & 10.3 & 96.8 \\
Levofloxacin & 30 & 3.2 & 3.2 & 100 \\
Total & 940 & 100 & 100 & \\
\hline
\end{tabular}


Table 3: Combinations of antimicrobial agents

\begin{tabular}{|c|c|c|c|c|}
\hline Combinations & Frequency & Percent & Valid percent & Cumulative percent \\
\hline Ceftriaxone+Metronidazole & 57 & 14.2 & 14.2 & 14.2 \\
\hline Cefotaxime+Metronidazole & 105 & 26.2 & 26.2 & 40.4 \\
\hline Ceftriaxone+Gentamycin & 18 & 4.5 & 4.5 & 44.9 \\
\hline Ceftriaxone+Amikacin & 26 & 6.5 & 6.5 & 51.4 \\
\hline Tinidazole+Ciprofloxacin & 44 & 10.9 & 10.9 & 62.3 \\
\hline Ampicillin+Gentamycin & 13 & 3.3 & 3.3 & 65.6 \\
\hline Cefotaxime+Metronidazole+Amikacin & 37 & 9.2 & 9.2 & 74.8 \\
\hline Cefotaxime+Ampicillin+Ciprofloxacin & 53 & 13.2 & 13.2 & 88.0 \\
\hline Ceftriaxone+Levofloxacin+Amikacin & 30 & 7.5 & 7.5 & 95.5 \\
\hline Amoxicillin+Gentamycin+Metronidazole & 18 & 4.5 & 4.5 & 100 \\
\hline Total & 401 & 100 & 100 & \\
\hline
\end{tabular}

Table 4: Class of antimicrobial agents

\begin{tabular}{lllll}
\hline Class & Frequency & Percent & Valid percent & Cumulative percent \\
\hline Cephalosporin & 326 & 34.7 & 34.7 & 34.7 \\
Amino glycoside & 142 & 15.1 & 15.1 & 79.8 \\
Imidazole & 224 & 23.8 & 23.8 & 73.6 \\
Penicillin & 121 & 12.9 & 12.9 & 86.5 \\
Fluoroquinolone & 127 & 13.5 & 13.5 & 100 \\
Total & 940 & 100 & 100 & \\
\hline
\end{tabular}

Table 5: Frequency of administration of AMA

\begin{tabular}{lllll}
\hline & Frequency & Percent & Valid percent & Cumulative percent \\
\hline OD & 92 & 9.8 & 9.8 & 9.8 \\
BD & 477 & 50.8 & 50.8 & 60.6 \\
TDS & 371 & 39.4 & 39.4 & 100 \\
Total & 940 & 100 & 100 & \\
\hline
\end{tabular}

Table 6: Route of administration of AMA

\begin{tabular}{lllll}
\hline Route & Frequency & Percent & Valid percent & Cumulative percent \\
\hline IV & 577 & 61.4 & 61.4 & 61.4 \\
Oral & 363 & 38.6 & 38.6 & 100 \\
Total & 940 & 100 & 100 & \\
\hline
\end{tabular}

The number of prescriptions where a single antimicrobial agent was used in the present study was 58 (12.6\%) patients. About 263 (57.3\%) prescriptions were noted with two antimicrobial agents. Three antimicrobial agents were administered to a total of 138 (30.1\%) prescriptions. fig. 1 shows that combination therapy with two antimicrobial agents was more preferred than use of three antimicrobial agents. And the use of a single antimicrobial agent was least preferred.

A study conducted by Kumar Abhijit et al. has shown that most commonly prescribed combination was that of ceftriaxone+amikacin and accounted for $51 \%$ prescriptions. The study was done using 300 prescriptions and noted that two antimicrobial agents were encountered in (38\%) prescriptions, and three drugs were prescribed in (46\%). The Government of India is planning to revise the antibiotic policy issued in 2011 and put a ban on over the counter availability of third generation antibiotics [26].

Dalfino et al. found the appropriateness of empiric antibiotic therapy was more frequently reached with wide spectrum combination therapy. They found that multiple-drug empiric regimens were appropriate in $97 \%$ of cases compared with $65 \%$ of single-drug regimens. Moreover, patients who achieved clinical success were more likely to have received antibiotic combination therapy [27].

Among the antimicrobial agent's cefotaxime 195 (20.7\%) was the most commonly prescribed drug and it was followed by metronidazole 180 (19.1\%). ceftriaxone 131 (13.9\%) was the third most commonly prescribed antimicrobial agent. It was followed by ciprofloxacin 97 (10.3\%). In the present study cephalosporins, 326 $(34.7 \%)$ was the most commonly prescribed class of antimicrobial agent as shown in fig. 3. And imidazoles 224 (23.8\%) was the second most commonly prescribed class of antimicrobial agents.

Kamath et al. in their cross-sectional study conducted in 154 patients have shown that the use of two antimicrobials agents was most common $48(31.17 \%)$ followed by three or more than three antimicrobial agents $36(23.38 \%)$ and the preferred drugs were metronidazole $72(15.52 \%)$ and cefotaxime $56(12.07 \%)$ which are similar to the present study [28]. Table 3 shows that the two drug combination of cefotaxime and metronidazole was most preferred, 105 (22.9\%) prescriptions.

Aminoglycosides accounted for 142 (15.1\%) prescriptions. They include amikacin 93 (9.9\%) and gentamycin 49 (5.2\%) prescriptions. In the present study, the use of penicillins was 121 (12.9\%) prescriptions. The frequency of use of ampicillin was 66 (7.1\%) prescriptions and amoxicillin 55 (5.9\%) prescriptions. The other class of antimicrobial agent that was used in the present study was fluoro-quinolones which accounted for 127 (13.5\%) prescriptions. Ciprofloxacin accounted for 97 (10.3\%) prescriptions, and that of levofloxacin was $30(3.2 \%)$ prescriptions.

The frequency of administration of antimicrobial agents is depicted in fig. 5 and it shows that twice a day administration of antimicrobial agents was the most preferred 477 (50.8\%) prescriptions. The least preferred frequency was once a day administration 92 (9.8\%) prescriptions. Thrice a day administration of antimicrobial agents was encountered in 371 (39.4\%) prescriptions.

The mean duration of prescription of antimicrobial agents in the present study was $4.78 \mathrm{~d}$ and the mean cost of drug treatment was 787.54 
rupees. The most cost effective regimen was that of aminoglycosides and imidazole. The intravenous route of administration was used in almost all patients in the study accounting for $61.4 \%$ prescriptions when compared to oral route $38.6 \%$ prescriptions. Initially, all patients were administered with an intravenous antimicrobial agent and it was later replaced by an oral antimicrobial agent.

Tomson et al. have shown that the excessive use of injectables is common in many developing countries [29]. This is in par with our study where antimicrobial agents were administered intravenously in $577(61.4 \%)$ prescriptions.

Viren Naik et al. conducted a study in 200 patients out of which 192 patients i.e. $96 \%$ were prescribed antibacterial drugs. The most commonly prescribing drug was metronidazole $44.8 \%$ followed by ciprofloxacin 38.5\%, gentamycin $36.9 \%$ and cefotaxime $32.2 \%$. Amikacin, ampicillin+cloxacillin and cephalexin were other antibacterials used. Use of cefazolin and norfloxacin was quite minimum i.e. $7.3 \%$ and $5.7 \%$ respectively. In $83.3 \%$ of the cases more than one antibacterial drug was given, and on an average 2.5 antibacterial drugs were used per patient in a range of 1 to 4 . The duration of the treatment with antibacterial drugs were $5 \mathrm{~d}$ to $15 \mathrm{~d}$, with an average duration of $6.9 \mathrm{~d}$. Oral route was used in $15.6 \%$ of patients while in $84.4 \%$ of cases they were given parenterally [30].

In the present study, $86.4 \%$ prescriptions had antimicrobial agents that were included in the WHO Essential drug list and only $13.6 \%$ of prescriptions contained drugs that were not included in the WHO Essential drug list [31]. Drug utilisation research (DUR) deals with the marketing, distribution, prescription, and use of drugs in society, with special emphasis on the resulting medical, social and economic consequences.

\section{Limitations of the study}

The present study was conducted at a single tertiary centre. Further studies if conducted at multiple centres can provide information about the widespread use of antimicrobial agents for surgical prophylaxis.

\section{CONCLUSION}

The use of antimicrobial agents in surgical prophylaxis has played a vital role in the prevention of post-operative infections and thereby reducing the hospital stay, cost incurred and mortality. The choice of antimicrobial agent was based on the local prevalence pattern of microorganisms.

In adherence with the guidelines the first dose of antimicrobial agent was given before the skin incision was performed. For surgical procedures that lasted for more than three hours additional dose of antimicrobial agent was given at intervals of one to two times the half-life of the drug after three hours of the first dose.

Guidelines recommend that prophylaxis should end within $24 \mathrm{~h}$ after the end of surgery, except in cardiothoracic surgery where it should be $72 \mathrm{~h}$. The intravenous administration of antibiotic prophylaxis immediately before or after the induction of anaesthesia is the most reliable method for ensuring effective serum concentration at the time of surgery. The antimicrobial agent chosen must cover all the most likely contaminating organisms.

There is need of polypharmacy and broad spectrum antimicrobial agents. Hence the chances of drug interactions, the emergence of resistance and higher cost have to be considered. Periodic assessment of the utilisation of antimicrobial agents is needed and the sensitivity pattern has to be established. Periodic surveys involving a larger number of subjects are needed for proper designing of antimicrobial policies and a stringent system for their implementation. After implementation of guidelines the adherence to the guidelines must be monitored.

\section{CONFLICTS OF INTERESTS}

All authors have none to declare.

\section{REFERENCES}

1. Bijoy Thomas, Leo Matthew, Jerrin Jose, Mohanraj Rathinavelu, Sriram Shanmugam, Krishna Kumar. Assessment of antibiotic sensitivity pattern of microorganisms and their costeffectiveness at a private corporate hospital in south india. Asian J Pharm Clin Res 2014;7:155-9.

2. Hiren M Chawda, Mahendra Patel, Divyesh Mandaviya, Manish Barvaliya, Tejas Patel, CB Tripathi. Utilisation pattern of antimicrobials among patients undergone midline laparotomy in four tertiary care teaching hospitals of gujarat, india: multicentric retrospective study. Asian J Pharm Clin Res 2013;6:145-50.

3. Sakaram Kashyap Khatri, Mahalaxmi Rathnanand, Nikhila R. Formulation and evaluation of wound healing activity of linezolid topical preparations on diabetic rats. Int J Appl Pharm 2016;8:30-6.

4. Pritesh Devbhuti, Chandana Sengupta, Achintya Saha. Studies on amikacin-induced lipid profile and peroxidation parameters and their control with ascorbic acid. Int J Curr Pharm Res 2010;2:76-81.

5. Harikesh Maurya, Susheel Kumar Dubey, Poonam Bisht, Monika Semwal, Sanjay Gandhi. An updates on the sepsis are causing multiple organ dysfunctions. J Crit Rev 2016;3:31-40.

6. Adiga MNS, Alwar MC, Pai MRSM, Adiga US. The pattern of antimicrobial agents uses in hospital deliveries: a prospective comparative study. J Med Pharm Allied Sci 2009;8:10.

7. Kulshrestha S, Aggrawal KK. Survey of a pattern of antimicrobial use in teaching hospital. Indian J Pharmacol 1984;16:395.

8. Sogaard H, Zimmermann-Nielsen C, Siboni K. Antibiotic resistant gram-negative bacilli in the aurological ward for male patients during a nine-year period: relationship to antibiotic consumption. J Infect Dis 1974;130:646-50.

9. Geubbels EL, Mintjes-de Groot AJ, Van den Berg JM. An operating surveillance system of surgical-site infections in the netherlands: results of the PREZIES national surveillance network. Preventive infectious door Surveillance. Infection Control Hospital Epidemiol 2000;21:311-8.

10. Leape LL, Brennan TA, Laird N. The nature of adverse events in hospitalised patients. Results of the harvard medical practice study II. N Engl J Med 1991;324:377-84.

11. Altemeier WA. Sepsis in surgery. Presidential address. Arch Surg 1982;117:107-12.

12. De Lissovoy G, Fraeman K, Hutchins V, Murphy D, Song D, Vaughn BB. Surgical site infection: incidence and impact on hospital utilisation and treatment costs. Am J Infect Control 2009;37:387-97.

13. Durando P, Bassetti M, Orengo G, Crimi P, Battistini A, Bellina D, et al. Adherence to international and national recommendations for the prevention of surgical site infections in Italy: results from a prospective observational study in elective surgery. Am J Infect Control 2012;40:969-72.

14. ASHP Therapeutic Guidelines on Antimicrobial Prophylaxis in Surgery. American Society of Health-System Pharmacists. Am J Health Syst Pharm 1999;56:1839-88.

15. Mangram AJ, Horan TC, Pearson ML, Silver LC, Jarvis WR. Guideline for prevention of surgical site infection. Am J Infect Control 1999;27:97-132.

16. Bush LM, Calmon J, Cherney CL. High-level penicillin resistance among isolates of enterococci: implications for treatment of enterococcal infections. Ann Intern Med 1989;110:515-20.

17. Herman DJ, Gerding DN. Screening and treatment of infections caused by resistant enterococci. Antimicrob Agents Chemother 1991;35:215-9.

18. Carlet J, Goldstein FW, Bleriot JP, Bahloul F, Dazza FE. Timentin in the antimicrobial treatment of nosocomial and polymicrobial infections. J Antimicrob Chemother 1986;17(Suppl C):149-59.

19. Bratzler DW, Houck PM. Antimicrobial prophylaxis for surgery: an advisory statement from the National Surgical Infection Prevention Project. Clin Infect Dis 2004;38:1706-15.

20. Adu A, Armour CL. Drug utilisation review of the third generation cephalosporins. Focus on ceftriaxone, ceftazidime and cefotaxime. Drugs 1995;50:423-39.

21. Anguzu J, Olila D. Drug sensitivity patterns of bacterial isolates from post-operative septic wounds in a regional referral hospital in Uganda. Afr Health Sci 2007;7:148-54.

22. Bergamini TM, Polk HC Jr. Pharmacodynamics of antibiotic penetration of tissue and surgical prophylaxis. Surg Gynecol Obstet 1989;168:283-9. 
23. Zelenitsky SA, Ariano RE, Harding GK, Silverman RE. Antibiotic pharmacodynamics in surgical prophylaxis: an association between intraoperative antibiotic concentrations and efficacy. Antimicrob Agents Chemother 2002; 46:3026-30.

24. Schwartz SI, Comshires G, Spencer FC, Dally GN, Fischer J, Galloway AC. Principles of surgery. 9th edition. Chapter 6 "surgical infections" NY: McGraw-Hill companies; 2010.

25. Khade A, Bashir M, Sheethal A. Prescription pattern in the department of surgery in a tribal district hospital of Andhra Pradesh, India. Ann Med Health Sci Res 2013;3:438-41.

26. Kumar Abhijit, Pushpawati Jain, Prerna Upadhyaya, Shipra Jain Antibiotic prescribing in various clinical departments in a tertiary care teaching hospital in Northern India. J Clin Diagn Res 2014;8:9-11.

27. Dalfino. The cost of care and antibiotic prescribing attitudes for community-acquired complicated intra-abdominal infections in Italy: a retrospective study. World J Emerg Surgery 2014;9:39.
28. Kamath. Prescribing patterns of antimicrobials in surgical departments in a tertiary care hospital in south india. Int J Pharm Sci Res 2014;5:1051-8.

29. Tomson G. Drug utilisation studies in Sri Lanka-Towards an understanding of medicine in society. Karolinska Institute, Stockholm; 1999. p. 1-7.

30. Shailesh Vadajiya, Viren Naik, Ashvin Mevada. A study of antimicrobial drug utilisation pattern and appropriateness in the surgical units of the civil hospital, Ahmedabad. Int J Pure Appl Biosci 2014;2:77-82.

31. The selection and use of Essential medicines. Report of $19^{\text {th }}$ WHO expert committee. WHO Technical Report Series 2014;985;114-7.

\section{How to cite this article}

- $\quad$ CS Brethis, S Thamizharasan, SA Sridevi, B Kalaiselvi, M Balaji Singh, K Vijaykumar. A prospective study of the pattern of use of antimicrobial agents in surgical PROPHYLAXIS in a tertiary care centre. Int J Pharm Pharm Sci 2017;9(1):283-287. 